\title{
Optimal preparation of high-entropy boride-silicon carbide ceramics
}

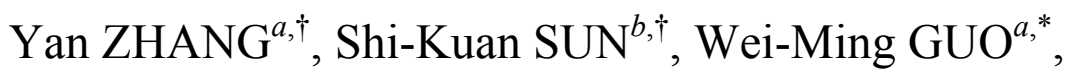 \\ Liang $\mathrm{XU}^{a}$, Wei ZHANG ${ }^{a}$, Hua-Tay LIN ${ }^{a,{ }^{*}}$ \\ ${ }^{a}$ School of Electron-mechanical Engineering, Guangdong University of Technology, Guangzhou 510006, China \\ ${ }^{b}$ Department of Materials Science and Engineering, University of Sheffield, Sheffield S1 3JD, UK
}

Received: June 2, 2020; Revised: August 27, 2020; Accepted: August 31, 2020

(C) The Author(s) 2020.

\begin{abstract}
High-entropy boride-silicon carbide (HEB-SiC) ceramics were fabricated using boridebased powders prepared from borothermal and boro/carbothermal reduction methods. The effects of processing routes (borothermal reduction and boro/carbothermal reduction) on the HEB powders were examined. HEB-SiC ceramics with $>98 \%$ theoretical density were prepared by spark plasma sintering at $2000{ }^{\circ} \mathrm{C}$. It was demonstrated that the addition of $\mathrm{SiC}$ led to slight coarsening of the microstructure. The HEB-SiC ceramics prepared from boro/carbothermal reduction powders showed a fine-grained microstructure and higher Vickers' hardness but lower fracture toughness value as compared with the same composition prepared from borothermal reduction powders. These results indicated that the selection of the powder processing method and the addition of $\mathrm{SiC}$ phase could contribute to the optimal preparation of high-entropy boride-based ceramics.
\end{abstract}

Keywords: high-entropy boride-silicon ceramics; borothermal reduction; boro/carbothermal reduction; microstructure; mechanical properties

\section{Introduction}

In recent years, high-entropy ultra-high temperature boride (HEB) ceramics have been extensively studied by combining the concepts of ultra-high temperature boride ceramic (UHTC) and high-entropy materials [1-3]. HEB ceramics were found to exhibit high hardness and superior oxidation resistance [4-6]. Accordingly, HEB ceramics are considered to possess potential for the broad application [4]. However, HEB ceramics suffered from the difficulty in densification mainly due to the strong covalent bonds and low

$\uparrow$ Yan Zhang and Shi-Kuan Sun contributed equally to this work.

* Corresponding authors.

E-mail: W.-M. Guo, guo1238@126.com;

H.-T. Lin, huataylin@comcast.net diffusion rate during the sintering process, as previously observed in traditional UHTC boride systems (e.g., $\mathrm{ZrB}_{2}$ and $\mathrm{HfB}_{2}$ ) $[4,5,7,8]$. Gild et al. [4] fabricated high-entropy boride ceramics by the combination of high-energy ball milling of the precursors and subsequent spark plasma sintering (SPS) at $2000{ }^{\circ} \mathrm{C}$. The as-sintered materials exhibited relatively higher hardness (21.0-22.5 GPa) and better oxidation resistance as compared to traditional boride ceramics. However, the relative density reported was only $92.4 \%$ due to the contamination of the powder during the milling procedure. The particle size and purity of powders were effectively improved by borothermal reduction and boro/carbothermal reduction, promoting sintering densification [3,9]. Our recent works reported that HEB ceramics could reach higher relative densities of $95.0 \%-99.2 \%$ by sintering the 
HEB powders derived from borothermal reduction and $96.3 \%-98.5 \%$ from boro/carbothermal reduction, respectively $[10,11]$. It was shown that HEB material with nearly full densification $(\mathrm{RD}=99.2 \%)$ and remarkable hardness $(28.3 \pm 1.6 \mathrm{GPa})$ could be achieved in the system of $\left(\mathrm{Hf}_{0.2} \mathrm{Zr}_{0.2} \mathrm{Ta}_{0.2} \mathrm{Cr}_{0.2} \mathrm{Ti}_{0.2}\right) \mathrm{B}_{2}[10]$.

By reviewing the developmental progress of ultrahigh temperature boride ceramics, $\mathrm{SiC}$ was added as a secondary phase into the $\mathrm{ZrB}_{2}$ and $\mathrm{HfB}_{2}$ system to reduce the sintering temperature and suppress the abnormal grain growth due to the pinning effect. Owing to the toughening effects resulting from the crack deflection and crack bifurcation, the fracture toughness of $\mathrm{ZrB}_{2}-\mathrm{SiC}$ and $\mathrm{HfB}_{2}-\mathrm{SiC}$ ceramics could be improved [12-14]. A few studies have been performed investigating the addition of SiC into HEB ceramic systems. In a recent study, $\mathrm{B}_{4}\left(\mathrm{HfMo}_{2} \mathrm{TaTi}\right) \mathrm{C}-$ $\mathrm{SiC}_{\mathrm{w}}$ showed an extremely high Vickers' hardness (35.4 GPa) and excellent oxidation resistance [15]. The introduction of $\mathrm{SiC}$ to the HEB ceramic system was reported to improve the densification behaviour as well as mechanical properties [16]. $\left(\mathrm{Ti}_{0.2} \mathrm{Zr}_{0.2} \mathrm{Hf}_{0.2} \mathrm{Nb}_{0.2} \mathrm{Ta}_{0.2}\right) \mathrm{B}_{2}-$ SiC was fabricated with high density $(>97 \%)$ by SPS at $1900{ }^{\circ} \mathrm{C}$, and the fracture toughness was increased by more than $30 \%$ [16]. Recently, Liu et al. reported the addition of $20 \mathrm{vol} \% \mathrm{SiC}$ into $\left(\mathrm{Ti}_{0.2} \mathrm{Zr}_{0.2} \mathrm{Hf}_{0.2} \mathrm{Nb}_{0.2} \mathrm{Ta}_{0.2}\right) \mathrm{B}_{2}$ high-entropy ceramics prepared by hot pressing sintering at $1800{ }^{\circ} \mathrm{C}$, improving the four-point flexural strength, fracture toughness, and hardness $H v_{0.2}$ from $339 \pm 17 \mathrm{MPa}, 3.81 \pm 0.40 \mathrm{MPa} \cdot \mathrm{m}^{1 / 2}$, and $23.7 \pm 0.7 \mathrm{GPa}$ to $447 \pm 45 \mathrm{MPa}, 4.85 \pm 0.33 \mathrm{MPa} \cdot \mathrm{m}^{1 / 2}$, and $24.8 \pm$ 1.2 GPa, respectively [17]. Nevertheless, more studies on HEB-SiC ceramic system would be still required to understand the effects of the powder processing methods and the addition of $\mathrm{SiC}$ on the densification behaviour and mechanical properties of HEB-SiC ceramics.

In this work, the self-synthesised HEB powders were mixed with SiC particles and sintered by SPS. In particular, two processing methods were examined comparing HEB powders prepared by borothermal reduction and boro/carbothermal reduction. The HEB ceramic systems, namely $\left(\mathrm{Hf}_{0.2} \mathrm{Zr}_{0.2} \mathrm{Mo}_{0.2} \mathrm{Nb}_{0.2} \mathrm{Ti}_{0.2}\right) \mathrm{B}_{2}$ and $\left(\mathrm{Hf}_{0.2} \mathrm{Mo}_{0.2} \mathrm{Ta}_{0.2} \mathrm{Nb}_{0.2} \mathrm{Ti}_{0.2}\right) \mathrm{B}_{2}$, were chosen in line with our previous studies [10,11]. The influence of the powder-processing routes on the phase assemblage, microstructure, and mechanical properties of HEB-SiC ceramics were emphatically investigated in this study.

\section{Experimental procedure}

The starting materials used in this study were $\mathrm{HfO}_{2}$ $(\sim 0.3 \mu \mathrm{m}$, purity $\geqslant 99.95 \%$, Beijing Founde Star Sci. \& Tech. Co., Ltd., China), $\mathrm{ZrO}_{2}(\sim 0.6 \mu \mathrm{m}, \geqslant 99.8 \%$, Changsha Xili Nanometer Lapping Tech. Co., Ltd., China), $\mathrm{Nb}_{2} \mathrm{O}_{5}(\sim 2.0 \mu \mathrm{m}, \geqslant 99.95 \%$, Beijing Founde Star Sci. \& Tech. Co, Ltd., China $), \mathrm{TiO}_{2}(\sim 21 \mathrm{~nm}$, $\geqslant 99.9 \%$, Xuancheng Jingrui New Material Co., Ltd., China), $\mathrm{Ta}_{2} \mathrm{O}_{5}(\sim 0.5 \mu \mathrm{m}, \geqslant 99.95 \%$, Zhuzhou Cemented Carbide Group Co., Ltd., China), $\mathrm{MoO}_{3}(\sim 1.0 \mu \mathrm{m}$, $\geqslant 99.9 \%$, Shanghai Naiou Nano Tech. Co., Ltd., China), boron $(\sim 1 \mu \mathrm{m},>95.60 \%$, Dandong Chemical Engineering Institute Co., Ltd., Dandong China), $\mathrm{B}_{4} \mathrm{C}$ $(\sim 1.5 \mu \mathrm{m}, \geqslant 99.9 \%$, Mudanjiang Diamond Boron Carbide Co. Ltd., China), and graphite $(\sim 2.0 \mu \mathrm{m}$, $\geqslant 99.9 \%$, Shanghai Colloid Chemical Co., Ltd., China). The appropriate amount of the raw powders was batched and mixed by roller milling $\left(\mathrm{J}_{\mathrm{M}}-6\right.$, Xiangtan Sanxing Instrument Co. Ltd., China) in ethanol for $24 \mathrm{~h}$ to target the fabrication of $\left(\mathrm{Hf}_{0.2} \mathrm{Zr}_{0.2} \mathrm{Mo}_{0.2} \mathrm{Nb}_{0.2} \mathrm{Ti}_{0.2}\right) \mathrm{B}_{2}$ and $\left(\mathrm{Hf}_{0.2} \mathrm{Mo}_{0.2} \mathrm{Ta}_{0.2} \mathrm{Nb}_{0.2} \mathrm{Ti}_{0.2}\right) \mathrm{B}_{2}$. Borothermal reduction (utilising mixed oxides and boron) and boro/ carbothermal reduction (utilising mixed oxides, boron carbide and graphite) were separately employed to prepare HEB powders by heat-treating the pre-mixed powders at $1600{ }^{\circ} \mathrm{C}$ for $1 \mathrm{~h}$ under vacuum. The phase fractions obtained by borothermal reduction were calculated as follows: $\mathrm{HEB}$ phase $=86.8 \mathrm{wt} \%, \mathrm{ZrB}_{2}=$ $5.5 \mathrm{wt} \%, \mathrm{~m}-(\mathrm{Zr}, \mathrm{Hf}) \mathrm{O}_{2}=5.3 \mathrm{wt} \%, \mathrm{t}-\mathrm{ZrO}_{2}=2.4 \mathrm{wt} \%$ for $\left(\mathrm{Hf}_{0.2} \mathrm{Zr}_{0.2} \mathrm{Mo}_{0.2} \mathrm{Nb}_{0.2} \mathrm{Ti}_{0.2}\right) \mathrm{B}_{2}$, and HEB $=97.3 \mathrm{wt} \%$, $\mathrm{m}-\mathrm{HfO}_{2}=2.7 \mathrm{wt} \%$ for $\left(\mathrm{Hf}_{0.2} \mathrm{Mo}_{0.2} \mathrm{Ta}_{0.2} \mathrm{Nb}_{0.2} \mathrm{Ti}_{0.2}\right) \mathrm{B}_{2}$, respectively [10]. For the boro/carbothermal reduction route [11], they were consisted of HEB phase $(94.0 \mathrm{wt} \%), \mathrm{m}-\mathrm{HfO}_{2}(4.1 \mathrm{wt} \%), \mathrm{t}-\mathrm{HfO}_{2}(1.9 \mathrm{wt} \%)$ for $\left(\mathrm{Hf}_{0.2} \mathrm{Zr}_{0.2} \mathrm{Mo}_{0.2} \mathrm{Nb}_{0.2} \mathrm{Ti}_{0.2}\right) \mathrm{B}_{2}$ product, and HEB $(90.4 \mathrm{wt} \%), \mathrm{m}-\mathrm{HfO}_{2}(9.0 \mathrm{wt} \%), \mathrm{t}-\mathrm{HfO}_{2}(0.6 \mathrm{wt} \%)$ for $\left(\mathrm{Hf}_{0.2} \mathrm{Mo}_{0.2} \mathrm{Ta}_{0.2} \mathrm{Nb}_{0.2} \mathrm{Ti}_{0.2}\right) \mathrm{B}_{2}$. More details on the purity and particle size on HEB powders synthesized could be found in Refs. [10] and [11]. $20 \mathrm{vol} \% \mathrm{SiC}$ $(\sim 0.3 \mu \mathrm{m}, \geqslant 99.9 \%$, Shanghai Xiangtian NewMaterials Co., Ltd., China) was mixed with the as-obtained HEB powders by roller milling $\left(\mathrm{J}_{\mathrm{M}^{-}}-6\right.$, Xiangtan Sanxing Instrument Co. Ltd., China) in ethanol for $24 \mathrm{~h}$ using silicon nitride milling media and acetone, and sintered by spark plasma sintering (H-HPD 10-FL, FCT System Gmbh, Germany) at $2000{ }^{\circ} \mathrm{C}$ in argon atmosphere for $10 \mathrm{~min}$ with a ramping rate of $150{ }^{\circ} \mathrm{C} / \mathrm{min}$ under uniaxial pressure of 
$30 \mathrm{MPa}$ (the same process parameters as the HEB ceramics without $\mathrm{SiC}$ additive [10,11]). Considering the limited milling media wear and mild milling conditions, it was hypothesised that the purity and particle size of the roller milled samples should have little variation, as compared to those starting from HEB powders without $\mathrm{SiC}$ additive in our previous work [10,11]. SiC addition with $20 \mathrm{vol} \%$ fraction was chosen in this work as this fraction was proved to be the optimal ratio in the previous studies of $\mathrm{ZrB}_{2}-\mathrm{SiC}$ and $\mathrm{HfB}_{2}-\mathrm{SiC}$ systems, aiming to improve the mechanical properties and oxidation resistance [13,18-20]. $\quad\left(\mathrm{Hf}_{0.2} \mathrm{Zr}_{0.2} \mathrm{Mo}_{0.2} \mathrm{Nb}_{0.2} \mathrm{Ti}_{0.2}\right) \mathrm{B}_{2}-\mathrm{SiC}$ and $\left(\mathrm{Hf}_{0.2} \mathrm{Mo}_{0.2} \mathrm{Ta}_{0.2} \mathrm{Nb}_{0.2} \mathrm{Ti}_{0.2}\right) \mathrm{B}_{2}-\mathrm{SiC}$ derived from borothermal reduction are hereafter labelled as HSBR-1 and HSBR-2, respectively. Similarly, the HEB samples from boro/carbothermal reduction are designated as HSBCR-1 and HSBCR-2.

The density of the HEB-SiC specimens was measured according to Archimedes' principle. The theoretical density of the HEB ceramics and HEB-SiC ceramics was calculated by rule of mixture. The theoretical density values of $\left(\mathrm{Hf}_{0.2} \mathrm{Zr}_{0.2} \mathrm{Mo}_{0.2} \mathrm{Nb}_{0.2} \mathrm{Ti}_{0.2}\right) \mathrm{B}_{2}$ and $\left(\mathrm{Hf}_{0.2} \mathrm{Mo}_{0.2} \mathrm{Ta}_{0.2} \mathrm{Nb}_{0.2} \mathrm{Ti}_{0.2}\right) \mathrm{B}_{2}$ ceramics was calculated to be 7.30 and $8.61 \mathrm{~g} / \mathrm{cm}^{3}$, respectively. The purity of the SPSed samples was examined by powder X-ray diffraction (XRD; $\mathrm{Cu} \mathrm{K \alpha}$ radiation, D8, Bruker Co., Germany) on powder samples obtained from the sintered HEB-SiC specimens, with the scanning step-size from $2 \theta=20^{\circ}-90^{\circ}$ set as $0.02^{\circ}$ dwelling for $0.2 \mathrm{~s}$ at each step. The lattice parameters of the products were calculated using the GSAS software package [21]. The carbon contents of HEB powders were determined using a carbon/sulfur analyser (CS-2000; ELTRA, Geremany) and oxygen contents of
HEB-SiC ceramics were determined using nitrogen/ oxygen determinator (TC600; Leco Corporation, St. Joseph, MI, USA). The microstructure was examined by scanning electron microscopy (SEM; Nova NanoSEM430, FEI, the Netherlands) equipped with energy dispersive X-ray spectra analysis (EDS; Quantax 200, Bruker Co.). The average grain size of the HEB phase in the SPSed HEB-SiC samples etched in an acid mixture (HF: $\left.\mathrm{HNO}_{3}: \mathrm{H}_{2} \mathrm{O}=1: 1: 3\right)$ for $1 \mathrm{~min}$ at room temperature was estimated from SEM images by Image-J software [22]. Vickers' hardness $\left(H v_{0.2}\right)$ of the ceramics was measured using a Vickers' Hardness Tester (HVS-30Z, Shanghai Taiming Optical Instrument Co., Ltd., China) with the load of $200 \mathrm{gf}$ for $15 \mathrm{~s}$, with at least 10 indentation points per sample. HEB-SiC ceramic toughness was measured by the indentation method with the load of $10 \mathrm{kgf}$ for $10 \mathrm{~s}$ (> 10 indentation points per sample) with the toughness value calculated accordingly [23].

\section{Results and discussion}

The relative density (RD) of the specimen was measured to be $(100.0 \pm 0.4) \%$ and $(99.1 \pm 0.1) \%$ for HSBR-1 and HSBR-2, respectively, indicative of nearly full densification, as listed in Table 1. Contrasted with HEB ceramics without $\mathrm{SiC}$ phase $(97.7 \%$ and $95.0 \%$ in the same composition without $\mathrm{SiC}$ in Ref. [10], 98.1\% and $98.5 \%$ in Ref. [11]), the densification of HEB ceramic material was improved by the introduction of $\mathrm{SiC}$. Close values of RD were determined for the HSBCR series samples from boro/carbothermal reduction, suggesting that there was no obvious difference regarding the densification response between processing

Table 1 Summary of the results on high-entropy boride-SiC ceramics in comparison with the reported results $[4,10,11]$

\begin{tabular}{|c|c|c|c|c|c|c|}
\hline Composition & $a(\AA)$ & $c(\AA)$ & $\begin{array}{l}\text { HE phase grain } \\
\text { size }(\mu \mathrm{m})\end{array}$ & $\begin{array}{l}\text { Relative density } \\
(\%)\end{array}$ & $H v(\mathrm{GPa})$ & $K_{\mathrm{IC}}\left(\mathrm{MPa} \cdot \mathrm{m}^{1 / 2}\right)$ \\
\hline HSBR-1: $\left(\mathrm{Hf}_{0.2} \mathrm{Zr}_{0.2} \mathrm{Mo}_{0.2} \mathrm{Nb}_{0.2} \mathrm{Ti}_{0.2}\right) \mathrm{B}_{2}-20 \mathrm{vol} \% \mathrm{SiC}$ & 3.0981 & 3.3645 & $3.99 \pm 0.73$ & $100.0 \pm 0.4$ & $25.8 \pm 1.2$ & $4.53 \pm 0.66$ \\
\hline HSBR-2: $\left(\mathrm{Hf}_{0.2} \mathrm{Mo}_{0.2} \mathrm{Ta}_{0.2} \mathrm{Nb}_{0.2} \mathrm{Ti}_{0.2}\right) \mathrm{B}_{2}-20 \mathrm{vol} \% \mathrm{SiC}$ & 3.0812 & 3.3059 & $4.18 \pm 0.96$ & $99.1 \pm 0.1$ & $26.2 \pm 1.8$ & $4.41 \pm 0.21$ \\
\hline HSBCR-1: $\left(\mathrm{Hf}_{0.2} \mathrm{Zr}_{0.2} \mathrm{Mo}_{0.2} \mathrm{Nb}_{0.2} \mathrm{Ti}_{0.2}\right) \mathrm{B}_{2}-20 \mathrm{vol} \% \mathrm{SiC}$ & 3.0980 & 3.3696 & $3.00 \pm 0.57$ & $98.6 \pm 0.2$ & $29.0 \pm 1.3$ & $3.80 \pm 0.33$ \\
\hline HSBCR-2: $\left(\mathrm{Hf}_{0.2} \mathrm{Mo}_{0.2} \mathrm{Ta}_{0.2} \mathrm{Nb}_{0.2} \mathrm{Ti}_{0.2}\right) \mathrm{B}_{2}-20 \mathrm{vol} \% \mathrm{SiC}$ & 3.0875 & 3.3058 & $3.75 \pm 0.89$ & $100.0 \pm 0.5$ & $28.1 \pm 0.9$ & $4.25 \pm 0.37$ \\
\hline$\left(\mathrm{Hf}_{0.2} \mathrm{Zr}_{0.2} \mathrm{Mo}_{0.2} \mathrm{Nb}_{0.2} \mathrm{Ti}_{0.2}\right) \mathrm{B}_{2}[10]$ & 3.0934 & 3.3526 & - & 97.7 & $26.3 \pm 0.7$ & - \\
\hline$\left(\mathrm{Hf}_{0.2} \mathrm{Mo}_{0.2} \mathrm{Ta}_{0.2} \mathrm{Nb}_{0.2} \mathrm{Ti}_{0.2}\right) \mathrm{B}_{2}[10]$ & 3.0820 & 3.3065 & - & 95.0 & $25.9 \pm 1.1$ & - \\
\hline$\left(\mathrm{Hf}_{0.2} \mathrm{Zr}_{0.2} \mathrm{Mo}_{0.2} \mathrm{Nb}_{0.2} \mathrm{Ti}_{0.2}\right) \mathrm{B}_{2}[11]$ & 3.0945 & 3.3592 & 1.45 & 98.1 & $26.3 \pm 1.8$ & - \\
\hline$\left(\mathrm{Hf}_{0.2} \mathrm{Mo}_{0.2} \mathrm{Ta}_{0.2} \mathrm{Nb}_{0.2} \mathrm{Ti}_{0.2}\right) \mathrm{B}_{2}[11]$ & 3.0821 & 3.2810 & 1.86 & 98.5 & $27.0 \pm 0.4$ & - \\
\hline$\left(\mathrm{Hf}_{0.2} \mathrm{Zr}_{0.2} \mathrm{Mo}_{0.2} \mathrm{Nb}_{0.2} \mathrm{Ti}_{0.2}\right) \mathrm{B}_{2}[4]$ & 3.092 & 3.345 & - & 92.3 & $21.9 \pm 1.7$ & - \\
\hline$\left(\mathrm{Hf}_{0.2} \mathrm{Mo}_{0.2} \mathrm{Ta}_{0.2} \mathrm{Nb}_{0.2} \mathrm{Ti}_{0.2}\right) \mathrm{B}_{2}[4]$ & 3.082 & 3.279 & - & 92.2 & $22.5 \pm 1.7$ & - \\
\hline
\end{tabular}


methods of borothermal reduction and boro/carbothermal reduction.

Powder XRD patterns of the HEB-SiC ceramics after SPS at $2000{ }^{\circ} \mathrm{C}$ are provided in Fig. 1(A). Characteristic peaks of a high-entropy boride phase were identified (space group of $P 6 / \mathrm{mmm}$ ). In comparison with $\mathrm{ZrB}_{2}$ and $\mathrm{HfB}_{2}$ (as demonstrated in Fig. 1, JCPDS PDF No. 65-8704 for $\mathrm{ZrO}_{2}$ and PDF No. 65-8678 for $\mathrm{HfO}_{2}$ ), the peaks of HEB phase shifted to the higher $2 \theta$ range, indicative of the formation of a smaller crystal cell. Meanwhile, the reflections of $\alpha$-SiC were detected at $2 \theta=34.1^{\circ}$ and $35.6^{\circ}$ (as shown in Fig. 1(B)) and the peak intensities were weaker than those of HEB ceramic phase. In addition, the contamination of the oxide impurity $\left(\mathrm{HfO}_{2}\right)$ was observed in the HEB-SiC ceramics, similar to our previously reported studies $[10,11]$. It should be noted that the intensities of $\mathrm{HfO}_{2}$ peaks in the product prepared by boro/carbothermal reduction were weaker than those by borothermal reduction. The oxygen contents in the as-obtained HEB-SiC ceramics were $2.08 \pm 0.01 \mathrm{wt} \%$ in HSBR-1, $2.46 \pm 0.02 \mathrm{wt} \%$ in HSBR-2, $1.86 \pm 0.04 \mathrm{wt} \%$ in HSBCR-1, and 2.29 $\pm 0.01 \mathrm{wt} \%$ in HSBCR-2. The residual carbon content was evident for the products
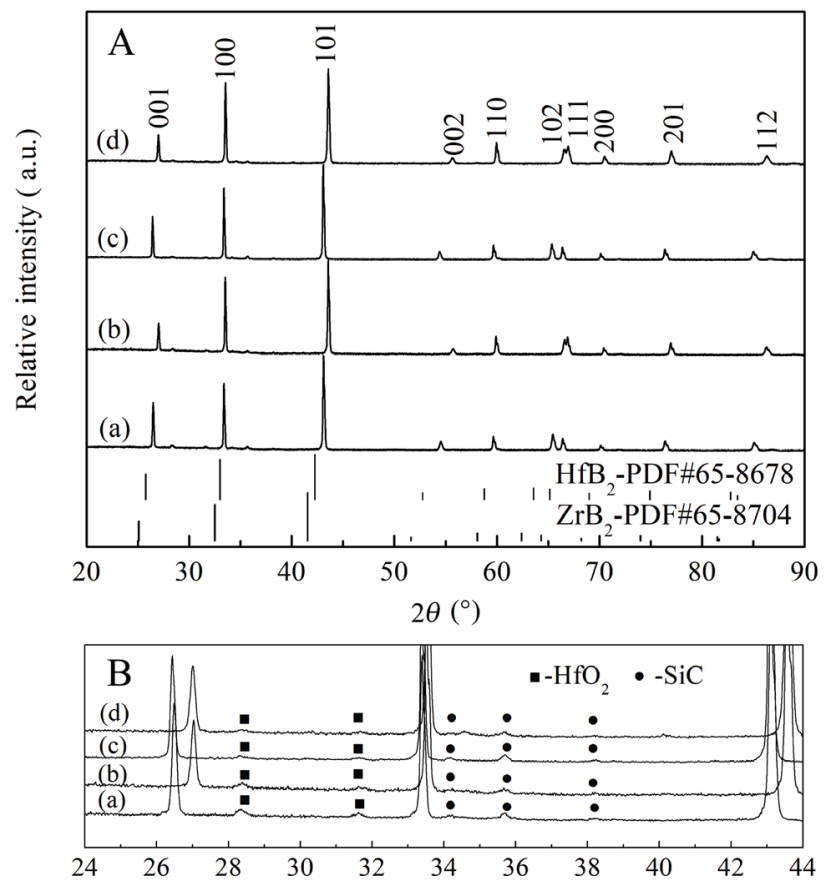

Fig. 1 (A) Powder XRD patterns of the HEB-SiC ceramics after SPS at $2000{ }^{\circ} \mathrm{C}$ : (a) HSBR-1, (b) HSBR-2, (c) HSBCR-1, and (d) HSBCR-2. (B) Enlarged view of the powder XRD patterns. The theoretical reflections of $\mathrm{ZrB}_{2}$ and $\mathrm{HfB}_{2}$ from JCPDS are also displayed for comparison. from boro/carbothermal reduction: $2.57 \mathrm{wt} \%$ in $\left(\mathrm{Hf}_{0.2} \mathrm{Zr}_{0.2} \mathrm{Mo}_{0.2} \mathrm{Nb}_{0.2} \mathrm{Ti}_{0.2}\right) \mathrm{B}_{2}$ and $1.65 \mathrm{wt} \%$ in $\left(\mathrm{Hf}_{0.2} \mathrm{Mo}_{0.2} \mathrm{Ta}_{0.2} \mathrm{Nb}_{0.2} \mathrm{Ti}_{0.2}\right) \mathrm{B}_{2}$, which was expected to react with the oxide impurities via carbothermal reduction reactions at high sintering temperature. The lattice parameters calculated by Rietveld refinement are also listed in Table 1. No obvious variations in lattice parameters were observed among the HEB phases prepared from borothermal reduction and boro/carbothermal reduction method.

EDS element mapping was employed to identify the impurity in HEB-SiC ceramics, shown in Fig. 2. The grey phase observed as the matrix was high-entropy boride, and the dark-grey phase was $\mathrm{SiC}$ phase. According to the element mapping results (Fig. 2), oxygen was detected in the white phase, which were identified as the oxide impurities indicated in the XRD results. Result of EDS mapping showed that the distribution of each element for each HEB-SiC ceramic was uniform. SiC phase exhibited homogeneous distribution in the HEB phase matrix with no agglomeration or solid solution with other elements from HEB.

The polished surface of the HEB-SiC ceramics after etching is shown in Fig. 3. Observations showed that $\mathrm{SiC}$ mainly located in triple grain junctions. The average grain size of HEB phase in the composition was measured to be $3.99 \pm 0.73 \mu \mathrm{m}$ in HSBR-1, $4.18 \pm 0.96 \mu \mathrm{m}$ in HSBR-2, 3.00 $\pm 0.57 \mu \mathrm{m}$ in HSBCR-1, and $3.75 \pm 0.89 \mu \mathrm{m}$ in HSBCR-2, respectively. In our previous study [11], HEB ceramics without $\mathrm{SiC}$ prepared from borothermal reduction showed a relatively finer microstructure and the average grain size was 1-2 $\mu \mathrm{m}$ (Table 1). The enhanced grain growth in the current HEB-SiC ceramics was apparent as compared with the HEB ceramics without SiC under the same sintering conditions. This was unexpected as $\mathrm{SiC}$ is typically considered to refine the microstructure of simple diboride ceramics (e.g., $\mathrm{ZrB}_{2}$ ), by means of pinning effects [18]. Whereas, the opposite phenomenon was observed for both HEB-SiC products prepared by the two powder processing routes. This suggests that the introduction of $\mathrm{SiC}$ into the HEB ceramics may be accompanied by liquid phase sintering, as oxygen impurity in $\mathrm{SiC}$ (e.g., amorphous $\mathrm{SiO}_{2}$ layer on $\mathrm{SiC}$ ) can form a eutectic phase. A liquid phase could accelerate the diffusion rate of the species involved in the densification mechanisms (dissolution-diffusionreprecipitation) [24], which further promotes the grain 


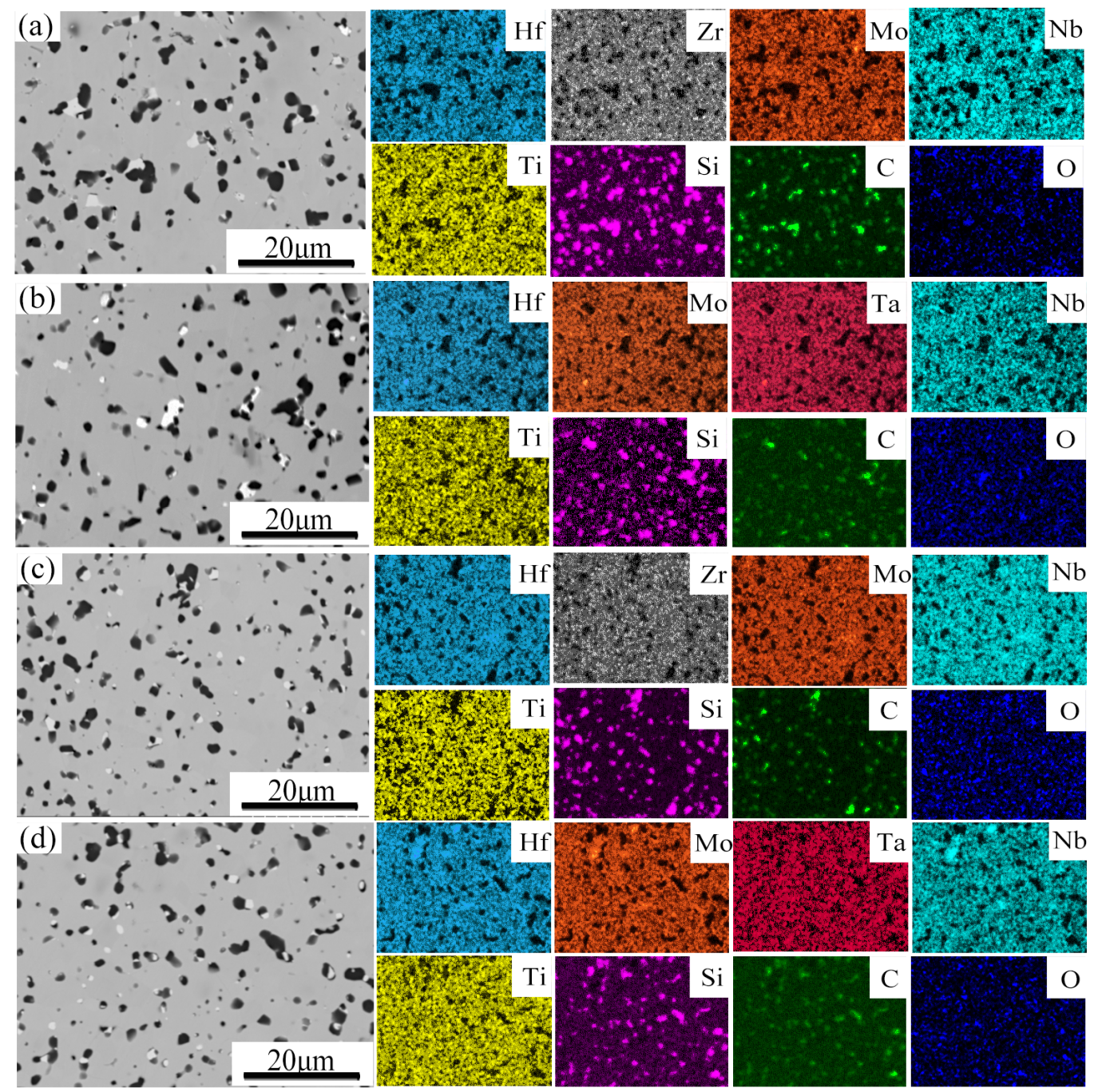

Fig. 2 EDS mapping of HEB-SiC ceramics: (a) HSBR-1, (b) HSBR-2, (c) HSBCR-1, and (d) HSBCR-2.
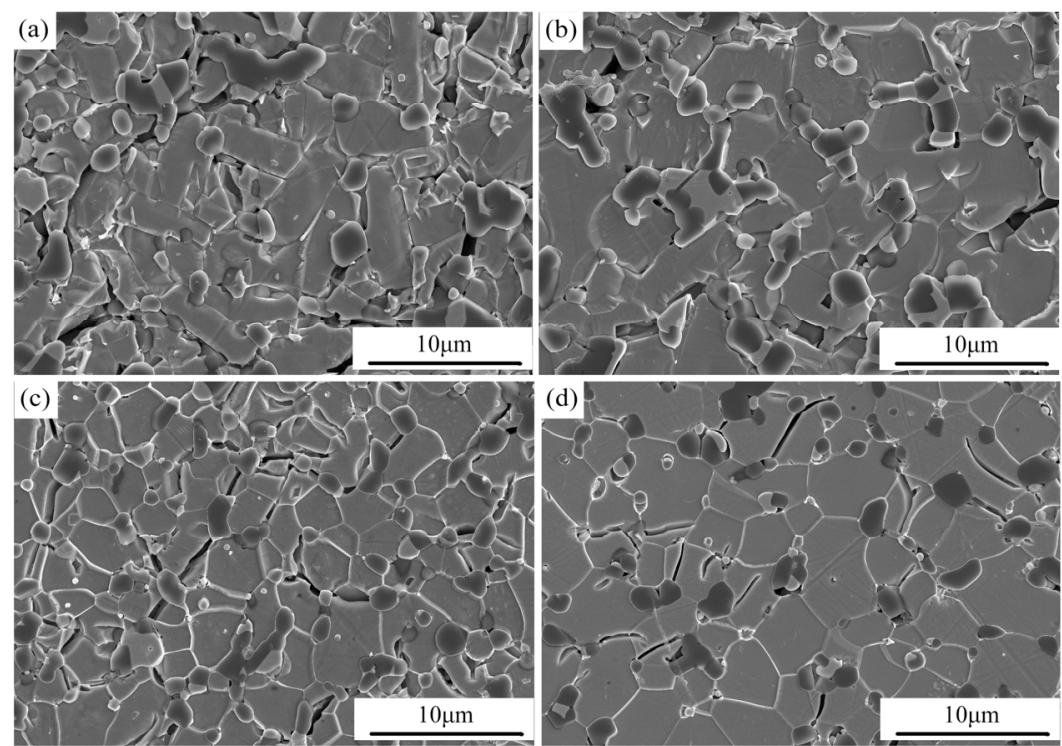

Fig. 3 SEM images of the polished surface of the HEB-SiC ceramics after etching: (a) HSBR-1, (b) HSBR-2, (c) HSBCR-1, and (d) HSBCR-2. 
growth of the HEB phase. Further experiments are under investigation to explain the mechanism and this work may provide some guidance for microstructure tuning of the HEB materials.

The average particle size of the starting HEB compounds from either borothermal reduction and boro/carbothermal reduction are measured to be in the range of $0.3-0.6 \mu \mathrm{m}[10,11]$. The microstructure of the HEB-SiC ceramics derived from borothermal reduction was expected to be comparable to boro/carbothermal reduction. However, from the microstructure analysis, it should be noted that a relatively finer grain size of HEB phase was observed in the HSBCR-1 and HSBCR-2 samples from boro/carbothermal reduction. This indicates that the processing routes of HEB powder affect the microstructure of the final HEB-SiC ceramics. This microstructure difference could be attributed to the presence of oxygen impurity and/or possible liquid phase, which promoted the coarsening of the boride grains. However, carbon residues present during boro/carbothermal reduction could facilitate the removal of oxygen impurities by carbothermal reduction, and hence the grain growth of HEB phase was suppressed during high temperature sintering $[13,14]$. In addition, finer $\mathrm{SiC}$ particles were also observed in the samples prepared by boro/carbothermal reduction due to the smaller grain size of HEB phase in HSBCR-1 and HSBCR-2. The isolated SiC particles also suppressed the mass transfer and the $\mathrm{SiC}$ grains growth by providing a longer diffusion path.

The fracture surfaces of HEB-SiC ceramics are shown in Fig. 4. Microstructure observations exhibited few pores and dense morphology in all compositions. The grey phase observed was high-entropy boride and the dark-grey phase was $\mathrm{SiC}$ particles. All the sintered specimens showed a transgranular fracture on the HEB phase. However, intergranular fracture behaviour on $\mathrm{SiC}$ grain was evident. A clear grain-pull-out and intergranular fracture of some $\mathrm{SiC}$ grains were observed (Figs. 4(a) and 4(b)), which was absent on the microstructures derived from boro/carbothermal reduction (Figs. 4(c) and 4(d)). This was likely caused by removal of oxygen impurity in boro/carbothermal reduction, and as a consequence, the grain boundary was purified and the bonding between grains was strong, leading to the transgranular fracture.

Measurements of Vickers' hardness and fracture toughness of the HEB-SiC ceramics were provided in Table 1. The hardness values were $25.8 \pm 1.2 \mathrm{GPa}$ and 26.2 $\pm 1.8 \mathrm{GPa}$ in HSBR-1 and HSBR-2, respectively. It was shown that $\mathrm{SiC}$ could improve the densification of HSBR system, but did not enhance the hardness mainly due to the grain coarsening effects (as discussed above). It was noteworthy that Vickers' hardness of HEB-SiC derived from boro/carbothermal reduction showed the higher values of $29.0 \pm 1.3 \mathrm{GPa}$ in HSBCR-1 and $28.1 \pm 0.9 \mathrm{GPa}$ in HSBCR-2. This could be attributed to the refined microstructure of HEB-SiC resulting from boro/carbothermal reduction. The toughness values were $4.53 \pm 0.66 \mathrm{MPa} \cdot \mathrm{m}^{1 / 2}$ and $4.41 \pm 0.21 \mathrm{MPa} \cdot \mathrm{m}^{1 / 2}$ in HSBR-1 and HSBR-2, $3.80 \pm 0.33 \mathrm{MPa} \cdot \mathrm{m}^{1 / 2}$ and $4.25 \pm$ $0.37 \mathrm{MPa} \cdot \mathrm{m}^{1 / 2}$ in HSBCR-1 and HSBCR-2, respectively.
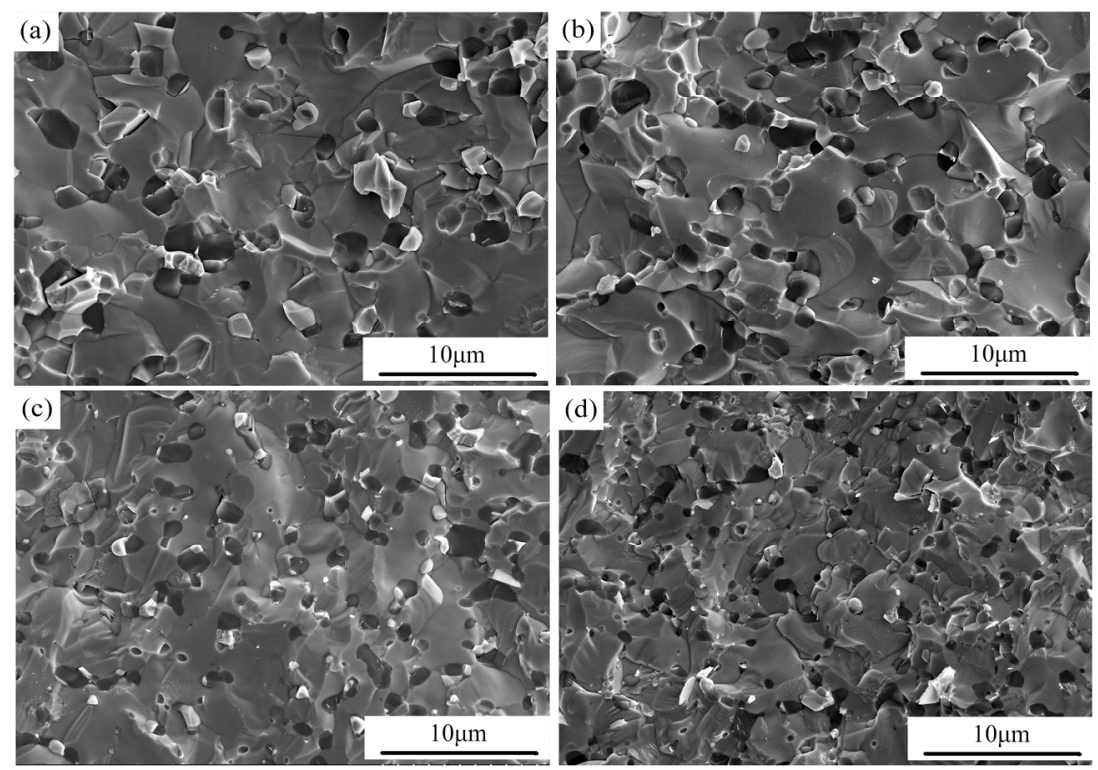

Fig. 4 SEM images of the fracture surface of the HEB-SiC ceramics: (a) HSBR-1, (b) HSBR-2, (c) HSBCR-1, and (d) HSBCR-2. 

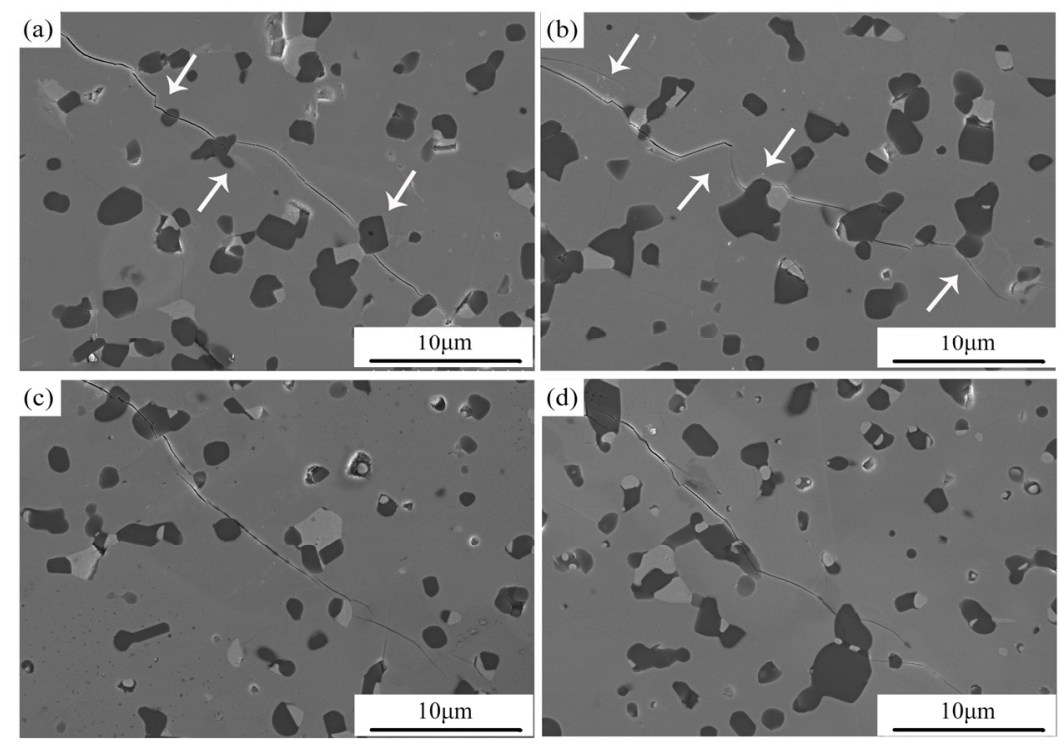

Fig. 5 SEM images of the crack propagation of the HEB-SiC ceramics: (a) HSBR-1, (b) HSBR-2, (c) HSBCR-1, and (d) HSBCR-2.

The HEB ceramics from borothermal reduction showed slightly higher toughness values, due to grain pull-out effect of some SiC grains (see Fig. 4), which was assumed to deflect the crack propagation. The crack propagation of the HEB-SiC ceramics were observed by SEM, shown in Fig. 5. Pronounced crack deflection and crack bridging was evidenced in the HEB-SiC samples derived from borothermal reduction, indicated by the white arrow in Figs. 5(a) and 5(b). Such crack deflection and bridging was believed to improve the toughness, attributed to the increasing path length for the crack fracture [12,13]. On the other hand, less crack deflection was apparent in HSBCR-1 and HSBCR-2 samples (Figs. 5(c) and 5(d)). Therefore, higher values of toughness in HSBR-1 and HSBR-2 were expected compared to HSBCR-1 and HSBCR-2.

It could be concluded that boro/carbothermal reduction route would not only refine the microstructure but also enhance the hardness of the final specimens. Meanwhile, the addition of $\mathrm{SiC}$ unexpectedly promoted the grain growth of high-entropy boride phase in comparison with HEB ceramics without SiC. It was shown that the fracture toughness of HEB-SiC from borothermal reduction slightly increased with $\mathrm{SiC}$ addition. These findings provided a better understanding of processing route, densification, and mechanical performance of high-entropy boride-silicon carbide ceramics. The results may inspire the further optimisation of both microstructure and mechanical properties of highentropy boride-based materials for potential applications.

\section{Conclusions}

The processing routes of high-entropy boride powders via borothermal and boro/carbothermal reduction were examined and compared on $\left(\mathrm{Hf}_{0.2} \mathrm{Zr}_{0.2} \mathrm{Mo}_{0.2} \mathrm{Nb}_{0.2} \mathrm{Ti}_{0.2}\right) \mathrm{B}_{2}-$ $\mathrm{SiC}$ and $\left(\mathrm{Hf}_{0.2} \mathrm{Mo}_{0.2} \mathrm{Ta}_{0.2} \mathrm{Nb}_{0.2} \mathrm{Ti}_{0.2}\right) \mathrm{B}_{2}-\mathrm{SiC}$ ceramics. The effects of $\mathrm{SiC}$ addition on the microstructure and the corresponding mechanical properties were also discussed. SiC was found to have little effect on the microstructure refinement. In comparison with those from borothermal reduction, the HEB-SiC ceramics from boro/carbothermal reduction exhibited the finer microstructure and thus relatively high Vickers' hardness values. The ultra-hard high-entropy borideSiC ceramic, $\left(\mathrm{Hf}_{0.2} \mathrm{Mo}_{0.2} \mathrm{Ta}_{0.2} \mathrm{Nb}_{0.2} \mathrm{Ti}_{0.2}\right) \mathrm{B}_{2}-20$ vol\% $\mathrm{SiC}$, with a high hardness value of $29.0 \mathrm{GPa}$ was obtained. Conversely, the intergranular fracture of some $\mathrm{SiC}$ grains was observed in the ceramics derived from borothermal reduction route, which led to the slight enhancement of fracture toughness. The current results indicate that the characteristics of the starting powders should also be considered when designing high-entropy boride-silicon carbide materials due to synergistic effects of processing route and secondary phase addition.

\section{Acknowledgements}

This work was financially supported by State Key Laboratory for Modification of Chemical Fibers and Polymer Materials, Donghua University (No. 19ZK0113), 
the Pearl River S and T Nova Program of Guangzhou (No. 201710010142), Science and Technology Planning Project of Guangdong Province (No. 2017A050501033), National Natural Science Foundation of China (Nos. 51402055, 51602060, and U1401247), and Guangdong Innovative and Entrepreneurial Research Team Program (Nos. 2013G061 and 2014YT02C049).

\section{References}

[1] Fahrenholtz WG, Hilmas GE, Talmy IG, et al. Refractory diborides of zirconium and hafnium. J Am Ceram Soc 2007, 90: $1347-1364$.

[2] Liu D, Liu HH, Ning SS, et al. Chrysanthemum-like high-entropy diboride nanoflowers: A new class of highentropy nanomaterials. J Adv Ceram 2020, 9: 339-348.

[3] Liu D, Wen T, Ye B, et al. Synthesis of superfine high-entropy metal diboride powders. Scripta Mater 2019, 167: $110-114$.

[4] Gild J, Zhang YY, Harrington T, et al. High-entropy metal diborides: A new class of high-entropy materials and a new type of ultrahigh temperature ceramics. Sci Rep 2016, 6: 37946.

[5] Tallarita G, Licheri R, Garroni S, et al. Novel processing route for the fabrication of bulk high-entropy metal diborides. Scripta Mater 2019, 158: 100-104.

[6] Gu JF, Zou J, Sun SK, et al. Dense and pure high-entropy metal diboride ceramics sintered from self-synthesized powders via boro/carbothermal reduction approach. Sci China Mater 2019, 62: 1898-1909.

[7] Zapata-Solvas E, Jayaseelan DD, Lin HT, et al. Mechanical properties of $\mathrm{ZrB}_{2}$ - and $\mathrm{HfB}_{2}$-based ultra-high temperature ceramics fabricated by spark plasma sintering. J Eur Ceram Soc 2013, 33: 1373-1386.

[8] Ni DW, Zhang GJ, Kan YM, et al. Hot pressed $\mathrm{HfB}_{2}$ and $\mathrm{HfB}_{2}-20 \mathrm{vol} \% \mathrm{SiC}$ ceramics based on $\mathrm{HfB}_{2}$ powder synthesized by borothermal reduction of $\mathrm{HfO}_{2}$. Int $\mathrm{J} \mathrm{Appl}$ Ceram Technol 2010, 7: 830-836.

[9] Liu D, Liu H, Ning S, et al. Synthesis of high-purity high-entropy metal diboride powders by boro/carbothermal reduction. J Am Ceram Soc 2019, 102: 7071-7076.

[10] Zhang Y, Guo WM, Jiang ZB, et al. Dense high-entropy boride ceramics with ultra-high hardness. Scripta Mater 2019, 164: 135-139.

[11] Zhang Y, Jiang ZB, Sun SK, et al. Microstructure and mechanical properties of high-entropy borides derived from boro/carbothermal reduction. J Eur Ceram Soc 2019, 39: 3920-3924.

[12] Buyakova SP, Knyazeva AG, Burlachenko AG, et al. Mechanical treatment of $\mathrm{ZrB}_{2}-\mathrm{SiC}$ powders and sintered ceramic composites properties. In: Proceedings of the Scientific-Practical Conference "Research and Development 2016”. Springer Cham, 2017: 521-530.

[13] Liu JX, Zhang GJ, Xu FF, et al. Densification, microstructure evolution and mechanical properties of WC doped $\mathrm{HfB}_{2}-\mathrm{SiC}$ ceramics. J Eur Ceram Soc 2015, 35: 2707-2714.

[14] Zou J, Zhang GJ, Vleugels J, et al. High temperature strength of hot pressed $\mathrm{ZrB}_{2}-20 \mathrm{vol} \% \mathrm{SiC}$ ceramics based on $\mathrm{ZrB}_{2}$ starting powders prepared by different carbo/ boro-thermal reduction routes. J Eur Ceram Soc 2013, 33: 1609-1614.

[15] Zhang HZ, Hedman D, Feng PZ, et al. A high-entropy $\mathrm{B}_{4}\left(\mathrm{HfMo}_{2} \mathrm{TaTi}\right) \mathrm{C}$ and $\mathrm{SiC}$ ceramic composite. Dalton Trans 2019, 48: 5161-5167.

[16] Shen XQ, Liu JX, Li F, et al. Preparation and characterization of diboride-based high entropy $\left(\mathrm{Ti}_{0.2} \mathrm{Zr}_{0.2} \mathrm{Hf}_{0.2} \mathrm{Nb}_{0.2} \mathrm{Ta}_{0.2}\right) \mathrm{B}_{2}-\mathrm{SiC}$ particulate composites. Ceram Int 2019, 45: 24508-24514.

[17] Liu JX, Shen XQ, Wu Y, et al. Mechanical properties of hot-pressed high-entropy diboride-based ceramics. $J A d v$ Ceram 2020, 9: 503-510.

[18] Guo WM, Zhang GJ, Wang PL. Microstructural evolution and grain growth kinetics in $\mathrm{ZrB}_{2}-\mathrm{SiC}$ composites during heat treatment. J Am Ceram Soc 2009, 92: 2780-2783.

[19] Mallik M, Kailath AJ, Ray KK, et al. Effect of SiC content on electrical, thermal and ablative properties of pressureless sintered $\mathrm{ZrB}_{2}$-based ultrahigh temperature ceramic composites. J Eur Ceram Soc 2017, 37: 559-572.

[20] Baharvandi HR, Mashayekh S. Effects of SiC content on the densification, microstructure, and mechanical properties of $\mathrm{HfB}_{2}-\mathrm{SiC}$ composites. Int J Appl Ceram Technol 2020, 17: 449-458.

[21] Toby BH. EXPGUI, a graphical user interface for GSAS. $J$ Appl Cryst 2001, 34: 210-213.

[22] Rueden CT, Schindelin J, Hiner MC, et al. ImageJ2: Image J for the next generation of scientific image data. BMC Bioinform 2017, 18: 529.

[23] Evans AG, Charles EA. Fracture toughness determinations by indentation. J Am Ceram Soc 1976, 59: 371-372.

[24] Monteverde F, Guicciardi S, Bellosi A. Advances in microstructure and mechanical properties of zirconium diboride based ceramics. Mater Sci Eng A 2003, 346: 310-319.

Open Access This article is licensed under a Creative Commons Attribution 4.0 International License, which permits use, sharing, adaptation, distribution and reproduction in any medium or format, as long as you give appropriate credit to the original author(s) and the source, provide a link to the Creative Commons licence, and indicate if changes were made.

The images or other third party material in this article are included in the article's Creative Commons licence, unless indicated otherwise in a credit line to the material. If material is not included in the article's Creative Commons licence and your intended use is not permitted by statutory regulation or exceeds the permitted use, you will need to obtain permission directly from the copyright holder.

To view a copy of this licence, visit http://creativecommons.org/licenses/by/4.0/. 